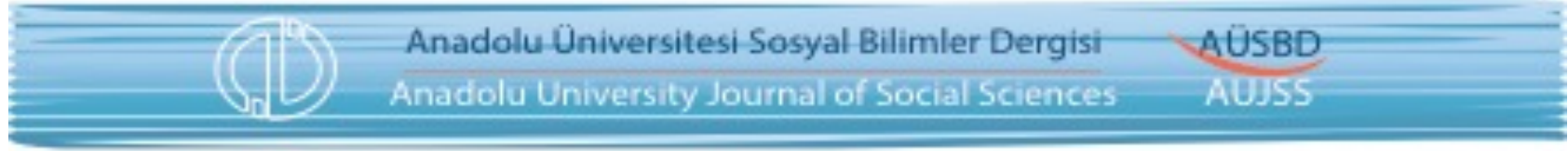

\title{
Foreign Exchange Intervention and Exchange Rate Volatility: Evidence from Turkey
}

\section{Döviz Kuru Müdahaleleri ve Kur Oynaklığı: Türkiye Örneği}

\author{
Dr. Öğr. Üyesi Oğuz Tümtürk ${ }^{1}$
}

Başvuru Tarihi: 19.03 .2018

Kabul Tarihi: 13.03.2019

\begin{abstract}
This paper investigates the effects offoreign exchange intervention by the Central Bank of the Republic of Turkey on the behavior of exchange rates during the float period starting with 2001 crisis. Even though the bank is apparently quite willing to intervene the foreign exchange market during the float period, the results suggest that intervention policies are completely ineffective. More specifically, the purchases operations do not have any statistically significant impact on the exchange rate returns and volatility while the central bank intervention sales exert an incorrectly signed effect on the levels of exchange rates and tend to raise volatility of exchange rates returns. Hence, the bank should avoid intervening foreign currency markets. Additionally, the tightening monetary policy in the form of rising the short run interest rates is effective for positive exchange rates returns; but not for dampening the volatility.
\end{abstract}

Keywords: Foreign exchange intervention, Exchange Rate Volatility, Volatility Asymmetry, EGARCH Modelling

Öz

Bu çalışmanın amacı, Türkiye Cumhuriyeti Merkez Bankası'nın yapmış olduğu döviz müdahalelerinin etkilerini 2001 krizi sonrası dalgalı kur sisteminin uygulandığı dönem içinde analiz etmektir. Banka söz konusu dönem boyunca döviz piyasasına müdahale etmekte istekli davranmakla birlikte, döviz müdahaleleri kur üzerinde arzu edilen etkiyi göstermemiştir. Daha açık bir şekilde belirtmek gerekirse, alım operasyonları ile döviz kurunun değişimi ve oynaklı̆̆ı arasında istatistiki olarak anlamlı bir ilişki bulunamamışken; merkez bankası satış operasyonları ise TL' nin hem değer kaybının hem de oynaklığının artmasına neden olmuştur. Bu yüzden banka döviz piyasasına müdahalelerden kaçınmalıdır. Buna ek olarak, kısa dönem faiz oranlarının arttırılması sureti ile uygulanacak daraltıcı para politikası ise beklendiği şekilde TL'nin değer kazanmasına yol açmakta ancak oynaklı̆̆ ise arttırmaktadır.

Anahtar Kelimeler: Döviz müdahaleleri, Döviz Kuru Oynaklı̆̆ı, Volatilite Asimetrisi, EGARCH Modellemesi

\footnotetext{
1 Ordu Üniversitesi Ünye İIBF, oguz.tumturk@gmail.com, ORCID: 0000-0002-1935-0858
} 


\section{Introduction}

There has been a long-standing debate over the effectiveness of the central bank intervention. One of the most provocative questions on the international economics is the whether the central bank interventions have any impacts on the level of exchange rate and its volatility. The studies regarding the foreign exchange intervention operations have found mixed results. Some studies argue that central bank interventions do not have any effect on the level of exchange rate; however, it might raise the volatility of exchange rate. Others claim that central bank interventions not only influence the level of the exchange rate but also smooth its volatility. A last group of studies, on the other hand, find evidences that central bank interventions have no effects both on the level and volatility. As mentioned by Sarno and Taylor (2001), the studies after the 1990s are largely supportive of the effectiveness of intervention and give more weight than the studies of the 1980s, which largely rejects the effectiveness of intervention. Hence, there has been an increasing support in favor of the intervention policies of the central banks in recent years. As suggested by Kim, Kortian and Sheen (2001), the central banks can influence the exchange rate process in two ways. The first one includes central bank interventions by reversing or smoothing its movement; therefore, it is associated with effects of intervention on the conditional mean of the changes of the exchange rate, and commonly described as "leaning against the wind". The second one, on the other hand, involves calming a disturbed market, and it is associated with changes in the conditional variance of the disturbance term.

Table 1. Foreign Exchange Intervention Data (Million US Dollar)

\begin{tabular}{|c|c|c|c|c|c|c|c|c|}
\hline Years & $\begin{array}{l}\text { Total } \\
\text { Amount of } \\
\text { Buying } \\
\text { Auctions }\end{array}$ & $\begin{array}{l}\text { Daily } \\
\text { Frequency } \\
\text { of Buying } \\
\text { Auctions }\end{array}$ & $\begin{array}{c}\text { Total } \\
\text { Amount } \\
\text { of } \\
\text { Selling } \\
\text { Auctions } \\
\end{array}$ & $\begin{array}{l}\text { Daily } \\
\text { Frequency } \\
\text { of Selling } \\
\text { Auctions }\end{array}$ & $\begin{array}{c}\text { Total } \\
\text { Amount of } \\
\text { Direct } \\
\text { Foreign } \\
\text { Purchases }\end{array}$ & $\begin{array}{c}\text { Daily } \\
\text { Frequency } \\
\text { of Direct } \\
\text { Foreign } \\
\text { Purchases }\end{array}$ & $\begin{array}{l}\text { Total } \\
\text { Amount of } \\
\text { Direct } \\
\text { Foreign } \\
\text { Sales } \\
\end{array}$ & $\begin{array}{c}\text { Daily } \\
\text { Frequency } \\
\text { of Direct } \\
\text { Foreign } \\
\text { (Sales) } \\
\end{array}$ \\
\hline 2002 & 654 & 27 & 0 & 0 & 16 & 1 & 12 & 2 \\
\hline 2003 & 5652 & 117 & 0 & 0 & 4229 & 6 & 0 & 0 \\
\hline 2004 & 4687 & 70 & 0 & 0 & 1283 & 1 & 9 & 1 \\
\hline 2005 & 7442 & 242 & 0 & 0 & 14565 & 6 & 0 & 0 \\
\hline 2006 & 4295 & 121 & 1000 & 2 & 5441 & 1 & 2105 & 3 \\
\hline 2007 & 10822 & 241 & 0 & 0 & 0 & 0 & 0 & 0 \\
\hline 2008 & 7584 & 194 & 100 & 2 & 0 & 0 & 0 & 0 \\
\hline 2009 & 4314 & 97 & 900 & 18 & 0 & 0 & 0 & 0 \\
\hline 2010 & 14865 & 238 & 0 & 0 & 0 & 0 & 0 & 0 \\
\hline 2011 & 6450 & 140 & 11210 & 79 & 0 & 0 & 2390 & 2 \\
\hline 2012 & 0 & 0 & 1450 & 15 & 0 & 0 & 1006 & 3 \\
\hline 2013 & 0 & 0 & 17610 & 125 & 0 & 0 & 0 & 0 \\
\hline 2014 & 0 & 0 & 9879 & 249 & 0 & 0 & 3151 & 1 \\
\hline 2015 & 0 & 0 & 12366 & 250 & 0 & 0 & 0 & 0 \\
\hline 2016 & 0 & 0 & 3400 & 83 & 0 & 0 & 0 & 0 \\
\hline 2017 & 0 & 0 & 0 & 0 & 0 & 0 & 0 & 0 \\
\hline 2018 & 0 & 0 & 0 & 0 & 0 & 0 & 0 & 0 \\
\hline Total & 66765 & 1487 & 57915 & 823 & 25534 & 15 & 8673 & 12 \\
\hline
\end{tabular}

Note: The data cover the period of April 2, 2002 and February 6, 2018. 
Exchange rate regime in Turkey is determined and conducted by the Central Bank of the Republic of Turkey (CBRT) together with the government; however, the CBRT is responsible for conducting interventions on the exchange rate. Following the 2001 economic crisis, Turkey started floating exchange rate against the US dollar, and exchange rates are determined by the supply and demand conditions in the foreign exchange market. In the floating exchange rate regime, the CBRT does not set any nominal or real exchange rate target; however, it takes measures to stop undervaluation and overvaluation of Turkish Lira (TL) for the purpose of reducing risks on the financial stability. Table 1 reports the summary of CBRT's foreign exchange interventions including buying and selling auctions and direct foreign exchange transactions over the period of 2002 and 2018. As shown in Table 1, the maximum total amount of buying auctions and direct purchases is observed in 2010 and 2005, respectively while the maximum total amount of selling auctions and direct sales is observed in 2013 and 2014, respectively.

This paper investigates the effects of foreign exchange intervention by the CBRT on the behavior of exchange rates: both the conditional mean and variance of exchange rate returns. To put it another way, the main aim of this paper is to answer the following question "can intervention operations of the CBRT influence the level and volatility of the exchange rate during the float period in Turkey?". Exchange rate level and volatility of the rate are analyzed by using Nelson's (1991) EGARCH model to deal with the commonly confronted features of financial times series such as volatility clustering and volatility asymmetry.

This paper is organized as follows: Section 2 summarizes some theoretical explanations of the intervention effectiveness. Section 3 surveys the empirical literature on the intervention operations while section 4 presents data. Section 5 develops a framework for the EGARCH model to estimate the effectiveness of the CBRT intervention operations. Finally, last section concludes.

\section{Central Bank Intervention and Theoretical Explanations for Intervention Effectiveness}

There are number of potential channels that a central bank's purchases and sales transactions may have effect on the exchange rates. The first one is known as "portfolio balance channel". In the literature, the portfolio balance channel is analyzed within the framework of a portfolio balance model of exchange rate determination and assumes that foreign and domestics assets are imperfect substitutes ${ }^{2}$. Portfolio balance channel involves sterilized foreign exchange intervention; hence, monetary base remains constant ${ }^{3}$. However, sterilized intervention leads investors to rebalance their portfolios by altering the supplies foreign and domestic assets. For example, a decrease in the supply of TL-denominated assets in the hands of the investors relative to the supply of dollar-denominated assets requires an increase in the relative price of TL-denominated assets. Therefore, sterilized intervention generates some changes in exchange rate through the portfolio balance channel.

\footnotetext{
2 Portfolio balance model of exchange rate determination simply states that investors take their portfolio decisions among the assets of various countries based on their relative expected returns.

3 A sterilized intervention is the purchase or sale of foreign currency by a central bank to influence the exchange value of the domestic currency. A sterilized intervention does not change the monetary base and involves successive two transactions: the sale or purchase of foreign currency, and an open market operation of the same size to sterilize the effect of the sale or purchase of foreign currency. On the other hand, if the purchase or the sale of the foreign currency is not followed by an open market operation, then it is called "unsterilized intervention". Unsterilized intervention, therefore, alters the monetary base in the economy.
} 
The second one is "monetary channel". Monetary channel, on the other hand, involves unsterilized foreign exchange intervention. That is, a central bank aims to increase or decrease monetary base by purchasing or selling foreign currency. Monetary channel directly affects exchange rates right after a monetary authority changes the amount of currency via foreign currency sales and purchases. According to the monetary channel, domestic and foreign assets are considered as "perfect substitutes"; hence, there is not any connection between bond supplies (or portfolio compositions) and exchange rate changes as claimed by portfolio channel.

The last one is called "signaling effect" of the intervention. Both monetary channel and portfolio balance channel have direct effect driving exchange rates. As stated by Edison (1993) "Both approaches admit intervention to affect the exchange rate indirectly by providing information about the views and intentions of the monetary authorities and thus influencing the expectations of exchange-market participants. This indirect influence is described as the signaling channel" (p.4). Portfolio balance channel is usually criticized by the argument that sterilized interventions have no direct effect on exchange rate. However, the sterilized intervention can still affect the spot rates through a signaling channel if it causes private agents to change their exchange-rate expectations; this is true even if domestic and foreign bonds are perfect substitutes ${ }^{4}$. As suggested by Sarno and Taylor (2001), signaling channel simply assumes that the monetary authorities have superior information to other market participants and they are willing to reveal this information through their actions in the foreign exchange market. If official intervention is expected to be operational through the signaling channel, there is an incentive for the authorities to declare clearly their policy intentions ${ }^{5}$.

\section{Literature}

There have been a large number of studies in the exchange rate literature investigating the effectiveness of central bank interventions. The objective of this section is to present the reviews of the related literature.

Dominguez and Frankel (1993) analyze the effectiveness of central bank interventions conducted by the FED and Bundesbank for the years between 1982 and 1988 through the portfolio channel. They find a statistically significant effect of FED and Bundesbank intervention on exchange rates during the sample period. Their results reveal that the general view in the early 1980's, that intervention policy is mostly not effective is no longer supported by the data. Dominguez (1998) investigates the impacts of foreign exchange intervention by the U.S., German, and Japan central banks on the behavior of exchange rates by using GARCH(1,1) over the 1977-1994 period. The results indicate that the interventions, particularly secret intervention operations which are those undertaken by central banks without public notification,

\footnotetext{
${ }^{4}$ More detailed discussion can be found in Edison (1993).

${ }^{5}$ However, there are many examples that monetary authorities often maintain secrecy of intervention operations. For example, Reserve Bank of Australia (RBA) began to release daily data late 1990s. Therefore, there are a large number of studies in the literature studying the secret intervention operations and effects on exchange rates such as Dominguez (1998), Beine and Leicourt (2004), Gnabo and Leicourt (2008). More detailed discussion of the reasons of secrecy of interventions can be found in Kim et al. (2000).
} 
generally increase volatility of exchange rates except for the period mid-1980s. Baillie and Osterberg (1997) investigate the motivations of buying and selling foreign currency and its effectiveness by the central banks of the U.S. and Germany. They describe the exchange rate returns as a Martingale- GARCH process and find no strong evidence that interventions have significant impact on the conditional mean of exchange rate returns. They also reveal that intervention is associated with slight increases in the volatility of exchange rates returns.

Kim et al. (2000) examine the key characteristics of foreign exchange intervention by the Reserve Bank of Australia for the period 1983-1997. They use EGARCH model and find contemporaneous positive correlation between the direction of intervention and the conditional mean and variance of exchange rate returns. They also conclude that large interventions have a stabilizing impact in the foreign exchange market in terms of direction and volatility. Beine, Bénassy-Quéré and Lecourt (2002) explore the impacts of official interventions on the short run evolution and volatility of the Deutsche mark/US dollar and the Japanese yen/US dollar exchange rates by the FIGARCH model. They find that central bank interventions exert an incorrectly signed effect on the levels of exchange rates and tend to raise volatility of exchange rate in the short run. They also conclude that FIGARCH model outperforms the traditionally used GARCH model.

Beine (2004) investigates the effects of central bank interventions focusing 1991-2001 period using multivariate GARCH model time varying conditional variances. His study provides evidence that interventions in foreign exchange markets tend to influence the conditional correlation between the major exchange rates, the Japanese yen and the Euro against the US dollar. The results also indicate that central bank interventions tend to increase the volatility of exchange rates and explain a significant amount of the covariance between the major currencies. Frenkel, Pierdzioch and Stadtmann (2005) study the empirical link between the intervention of the Bank of Japan (BOJ) and exchange rate volatility based on the financial press reports of BOJ interventions since official BOJ daily intervention is not available to the public. They find a positive link between the BOJ interventions and volatility of the Japanese yen/US dollar exchange rate. Kearns and Rigobon (2005) analyze whether foreign exchange interventions are effective for daily data from Australia and Japan and reveal that the impact of central bank interventions is economically and statistically significant to stabilize the exchange rates. For example, they conclude that a 100 million U.S. dollar purchase appreciates the Australian dollar by 1.3$1.8 \%$ but the yen by just $0.2 \%$.

Dominguez (2006) investigates dollar interventions by the G3 governments (the U.S., Japan and Germany) since 1989. Using intra-daily and daily exchange rate and intervention data, Dominguez aims to analyze the influence of interventions on exchange rate volatility, and finds little evidence that interventions increase longer-term volatility. Fatum (2008) analyzes the effects of official, daily Bank of Canada (BOC) intervention in the Canadian Dollar/US dollar exchange rate over the 1995-1998 period. Using an event study methodology and different criteria for effectiveness, the study does not reveal any significant effects of BOC intervention in terms of dampening volatility. Fatum also shows that BOC intervention appears moderately effective in moving the Canadian dollar/US dollar exchange rate over a 
number of days following the intervention events. Utsunomiya (2013) analyses the effect of intervention frequency on the yen/dollar market from April 1991 to December 2005 by using nonlinear methodology. The study estimates the effectiveness of intervention and its frequency using the double threshold GARCH model and concludes that high frequency intervention stabilizes the exchange rate volatility especially when the yen appreciates.

Even though there are a large number of studies in the international literature regarding the effectiveness of central bank interventions, there are relatively few studies exploring the foreign exchange interventions in the case of Turkey. Tuna (2011) investigates the effectiveness of CBRT intervention on the conditional volatility and the direction of exchange rate returns in Turkey during the float period by using EGARCH framework over the period of 2001 and 2005. Tuna finds little evidence in favor of the effectiveness of intervention operations and indicates that foreign exchange (FX) selling auctions increase the volatility of exchange rate. Tunay (2008) analyzes the effects of Turkish Central Bank's interventions over currency rate volatility between 1999 and 2008 by using ARFIMA-GARCH and ARFIMAFIGARCH models. He finds that CBRT interventions raise the exchange rate volatility and CBRT should avoid intervening currency markets in Turkey. Cicek (2014) examines the effects of the CBRT's foreign exchange interventions via auctions on the level and volatility of the TL/US dollar exchange rate between 2009 and 2014 by using EGARCH Model. The results reveal that interventions have no significant impact on the level of the exchange rate, and the impact of the presence of the CBRT on the exchange rate volatility is not statistically significant; however, intervention volume significantly raises exchange rate volatility. Moreover, there is no significant evidence of presence of asymmetric volatility and leverage effect. Akinci, Culha, Ozlale and Sahinbeyoglu (2006) investigate the effectiveness of foreign exchange interventions for the Turkish economy conducted by the CBRT after the 2001 crisis period by time varying-parameter model. They conclude that the purchase interventions in the second half of 2003 are relatively more effective; therefore, the CBRT should not hesitate to intervene in the market in the form of large purchases. Gok, Ozturk and Ozkul (2014) study the effects of CBRT foreign exchange interventions on US dollar/TL exchange rate level and volatility over the period of 2001 and 2015. They present the evidence that intervention operations generate a positive pressure on exchange rate level; additionally, the amount and frequency of intervention operations have reverse effects on the exchange rate level and partially contribute to stability of exchange rates.

\section{Data}

The US dollar/TL exchange rate data $\left(S_{t}\right)$ over the period April 2002 to February 2018 (see Fig. 1) are obtained from the CBRT Electronic Data Delivery System (EDDS). The sample consists of 3994 daily observations. The exchange rate is defined as the US dollar price of one unit of TL; therefore, an increase in exchange rate represents the appreciation of TL against US dollar. The exchange rate return series are calculated as the difference in natural logarithms between successive daily quotations for the exchange rates multiplied by $100\left(\Delta \mathrm{S}_{\mathrm{t}}=100 \mathrm{x} \log \left(\mathrm{S}_{\mathrm{t}} / \mathrm{S}_{\mathrm{t}-1}\right)\right.$. Both the overnight interest rate and the CBRT foreign 
exchange intervention data for Turkey are obtained from CBRT while the overnight interest rates data (FED Funds rate) for the U.S are obtained from the Federal Reserve (FRED) ${ }^{6}$.

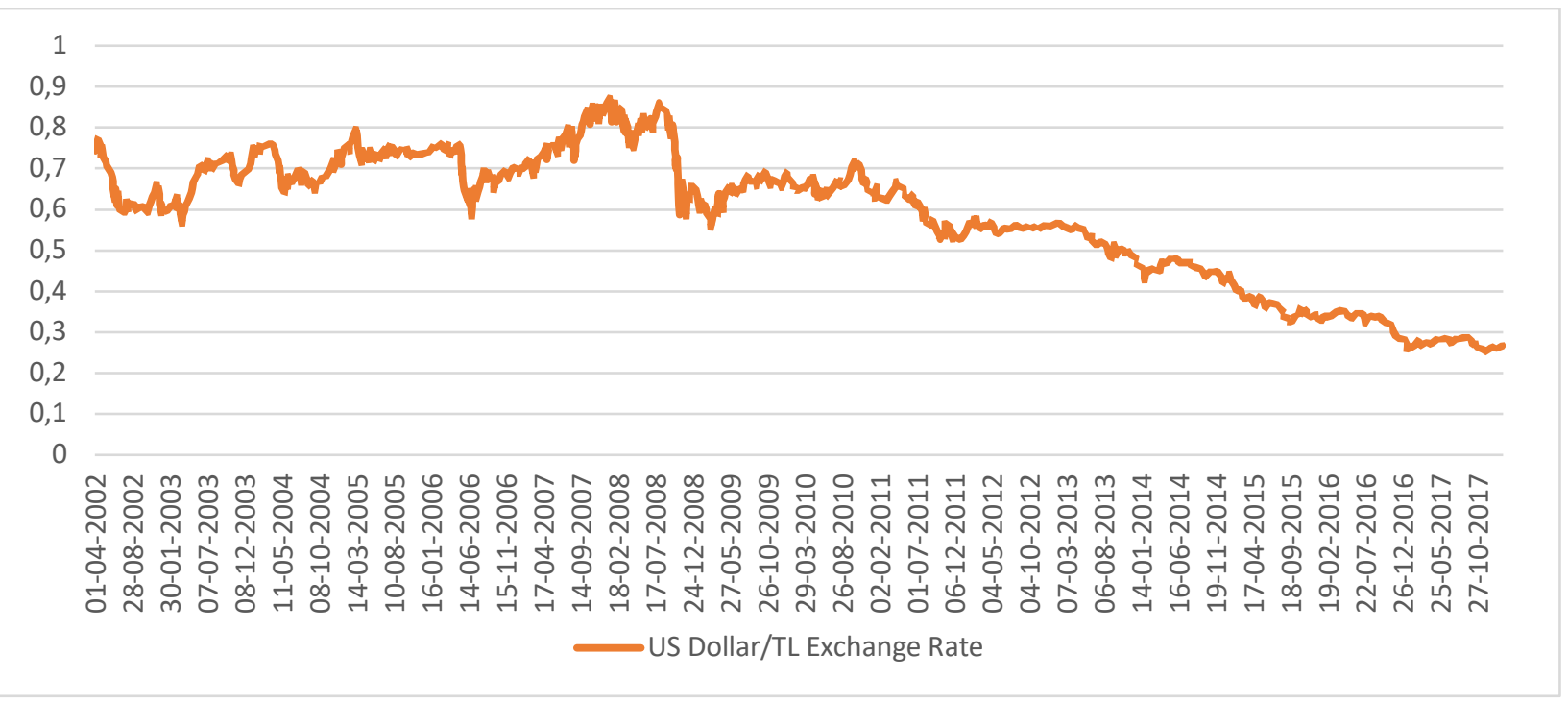

Figure 1. Daily US Dollar/TL Exchange Rate: April 2002- February 2018

\section{Daily US Dollar/TL Returns}

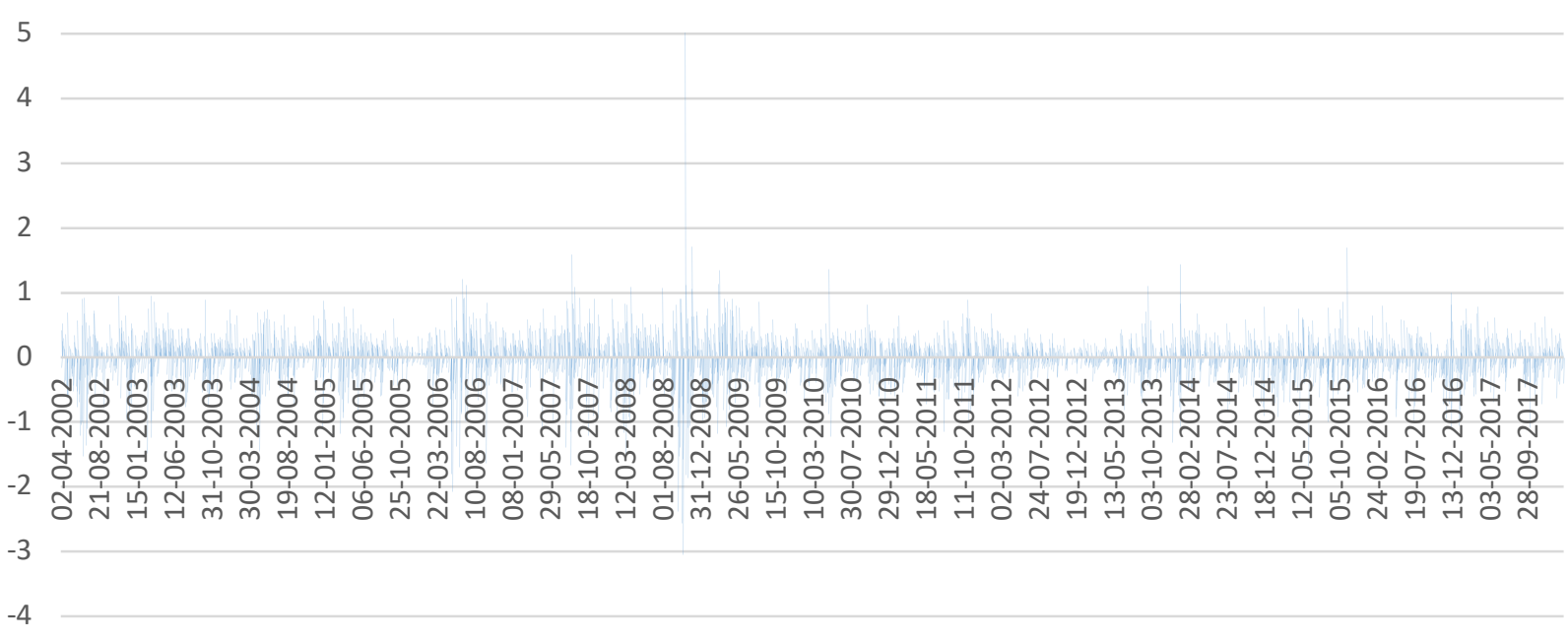

Figure 2. Daily US Dollar /TL Returns: April 2002- February 2018

\footnotetext{
${ }^{6} \mathrm{CBRT}$ intervention data includes the foreign exchange buying/selling auctions and direct foreign exchange purchases and sales.
} 


\section{Modelling Exchange Rate Volatility}

\section{Financial Time Series and GARCH Models}

One of the most common observed characteristics of financial time series is the continuously changing volatility of the series through time. Engle (1982) proposed ARCH models by the aim of estimating the time-dependent volatility as a function of observed past volatility. Later, Bollerslev (1986) introduced GARCH model by generalizing the ARCH model to include lagged values of the conditional variance. Following the Bollerslev's pioneering work, many studies investigating the exchange rate volatility have employed the simplest order of $\operatorname{GARCH}(1,1)$ model. GARCH models implicitly assume that positive (good news) and negative unanticipated shocks (bad news) have same impact on the conditional variance of the disturbance term or volatility of exchange rates. This is known as "volatility symmetry".

Table 2. Descriptive Statistics on Daily Exchange Rate (US Dollar/TL) Returns

\begin{tabular}{|l|c|}
\hline Mean & -0.0112 \\
\hline Max & 5.18 \\
\hline Min & -3.06 \\
\hline Skewness & -0.194 \\
\hline Kurtosis & 18.689 \\
\hline Shapiro-Wilk W Test for normality (test stat.(P-Value)) & $0.915(0.000)$ \\
\hline ARCH-LM(1) Test (test stat.(P-Value)) & $54.87(0.000)$ \\
\hline
\end{tabular}

Table 3. Unit Root Characteristics of the Data

\begin{tabular}{|c|c|c|}
\hline Variables & $\begin{array}{l}\text { ADF Test Stat. } \\
\left.\text { [\%5 Critical Values }{ }^{\mathrm{a}}\right]\end{array}$ & $\begin{array}{c}\text { Phillips-Perron Test Stat. } \\
\text { [\%5 Critical Values] }\end{array}$ \\
\hline \multicolumn{3}{|l|}{$\Delta S_{t}$} \\
\hline Trend and Constant & $-35.051[-3.410]$ & $-50.636[-1.950]$ \\
\hline Constant & $-35.065[-2.860]$ & $-50.682[-2.860]$ \\
\hline None & $-35.083[-1.950]$ & $-50.669[-3.410]$ \\
\hline \multicolumn{3}{|l|}{ SPREAD } \\
\hline Trend and Constant & $-4.554[-3.410]$ & $-4.605[-3.410]$ \\
\hline Constant & $-3.175[-2.860]$ & $-3.894[-2.860]$ \\
\hline None & $-4.088[-1.950]$ & $-4.269[-1.950]$ \\
\hline \multicolumn{3}{|l|}{ VOLBUY } \\
\hline Trend and Constant & $-29.822[-3.410]$ & $-47.460[-3.410]$ \\
\hline Trend & $-29.267[-2.860]$ & $-47.120[-2.860]$ \\
\hline None & $-28.170[-2.860]$ & $-46.354[-1.950]$ \\
\hline \multicolumn{3}{|l|}{ VOLSELL } \\
\hline Trend and Constant & $-7.659[-3.410]$ & $-44.513[-3.410]$ \\
\hline Constant & $-7.563[-2.860]$ & $-44.069[-2.860]$ \\
\hline None & $-7.192[-1.950]$ & $-43.244[-1.950]$ \\
\hline
\end{tabular}


Table 2 summarizes the descriptive summary statistics for the return series and reveals some preliminary findings roughly during the whole sample period. The return series exhibit the usual features of GARCH models such as excess kurtosis and negative skewness ${ }^{7}$. While Shapiro-Wilk W test (1965) for normality reveals that returns series are not normally distributed. Moreover, I fit a constant-only model by OLS and investigate the ARCH effects of returns series by using Engle's (1982) Lagrange multiplier test (ARCHLM Test). The test result reports that the null hypothesis of no $\mathrm{ARCH}(1)$ effect is rejected at five percent significance level and the errors are autoregressive conditional heteroskedastic. Finally, as stated by Westerfield (1977) and Hsieh (1988), leptokurtic daily exchange rate returns suggest the volatility clustering (see Fig. 2) which represents the fact that large changes are tend to be followed by large changes and small changes are tend to be followed by a small changes ${ }^{8}$. All these preliminary results suggest that the US dollar/TL exchange rate returns are forecastable by GARCH models. Finally, as seen in Table 3, the conventional unit root test results reveal that one can reject the null of a unit root at five percent significance level. Phillips-Perron (1988) test is also conducted in addition to the Augmented Dickey Fuller (1979) test to employ Newey-West (1987) standard errors to account for serial correlation.

\section{Volatility Asymmetry and EGARCH Model}

A general GARCH specification implies a symmetric effect of an unanticipated shocks. That is, a positive or negative unanticipated shock $\left(\varepsilon_{t}^{2}\right)$ makes no difference to the conditional variance $\left(\sigma_{t}^{2}\right)$ in the succeeding periods; however, only the magnitude of the shocks makes difference. On the other hand, positive and negative shocks might have different weights on conditional volatility of exchange rates ${ }^{9}$. Since "volatility asymmetry" implies that positive and negative shocks in return series have asymmetric effect on exchange rate volatility, I employ the Nelson's (1991) EGARCH model to capture the possible asymmetric effect by the inclusion of negative shocks or standardized residuals into the conditional variance equation. The model in this paper is $\operatorname{EGARCH}(1,1)$ with Student's t-distribution for the standardized residuals as shown below with conditional mean equation of the change of the exchange rate (1) and conditional variance equation $(2)^{10}$ :

$$
\begin{gathered}
\Delta s_{t}=\alpha_{c}+\alpha_{v o l b} V O L B U Y+\alpha_{v o l s} \text { VOLSELL }+\alpha_{\text {spread }} S P R E A D+\alpha_{\text {hol }} D H O L+\varepsilon_{t} \\
\varepsilon_{t}=z_{t} \sigma_{t} \sim t\left(0, \sigma_{t}^{2}, \rho\right), z_{t} \sim N(0,1)
\end{gathered}
$$

\footnotetext{
${ }^{7}$ Excess kurtosis implies that tails are fatter than normal distribution. Distributions with kurtosis greater than 3 are said to be "leptokurtic". A leptokurtic distribution has tails that asymptotically approach zero more slowly than a normal distribution, and therefore produces more outliers than the normal distribution. Negative skewness implies that there are more extreme measurements in the left tail of the distribution than right tail.

8 The term of "volatility clustering" is first mentioned by Mandelbrot (1963).

9 For example, Black (1976) and Nelson (1991) state that a large unanticipated negative shock in the market is more likely to lead to higher volatility than a large positive shock for risk-averse investors. This is also known as "negative leverage effect".

${ }^{10}$ The first-order generalized ARCH model or GARCH is the most commonly used specification for the conditional variance in empirical work and is typically written GARCH $(1,1)$. For example, Bollerslev (1986), Hsieh (1989) and Bailie and Bollerslev (1989), Dominguez (1998) stated that GARCH(1,1) is the most appropriate model for daily exchange rate data.
} 


$$
\begin{aligned}
\ln \left(\sigma_{t}^{2}\right)= & \beta_{c}+\beta_{1} z_{t-1}+\beta_{2} \ln \left(\sigma_{t-1}^{2}\right)+\beta_{3}\left(\left|z_{t-1}\right|-\sqrt{\frac{2}{\pi}}\right)+\beta_{v o l b} V O L B U Y+\beta_{v o l s} V O L S E L L+ \\
& \beta_{\text {spread }} S P R E A D+\beta_{h o l} D H O L
\end{aligned}
$$

where $\Delta \mathrm{S}_{\mathrm{t}}=100 \mathrm{x} \log \left(\mathrm{S}_{\mathrm{t}} / \mathrm{S}_{\mathrm{t}-1}\right)$ is the nominal exchange rate returns and calculated as the difference in natural logarithms of the successive daily rates; VOLBUY denotes the daily amount of the CBRT purchases; VOLSELL denotes the daily amount of the CBRT sales ${ }^{11}$. These two variables measure whether the presence of the CBRT in the foreign exchange market can explain the exchange rate returns and volatility on the day of intervention. SPREAD is the difference between Turkey and the U.S. overnight interest rates and includes the possible impact of the monetary policy conducted by the CBRT on the exchange rate process. DHOL is a $(1,0)$ holiday dummy variable that is equal to one on the day following the market being closed for any reason ${ }^{12}$. Exogenous variables included in the both conditional mean and variance equations given above are exchange rate intervention variables (VOLBUY and VOLSELL), spread and holiday dummy variables. $\varepsilon_{t}$ is the disturbance term and $\sigma_{t}^{2}$ is the time-dependent conditional variance of the disturbance term. The conditional distribution of disturbance term is Student's $t$ with variance $\sigma_{t}^{2}$ and degrees of freedom $\rho . z_{t}$ is, on the other hand, standardized residuals and distributed standard normal.

In the conditional variance equation, $\beta_{1}$ parameter is known as "leverage or volatility asymmetry parameter" and represents the asymmetry effect of positive and negative shocks on the volatility. Negative asymmetry term implies that a large unanticipated negative shock in the market leads to higher volatility than a large positive shock of the same size. Similarly, positive asymmetry term implies that positive shock has a greater impact on volatility rather than the negative shocks of the same magnitude. $\beta_{2}$ parameter measures the "GARCH effect" and stands for the persistence of the past conditional volatility explaining current volatility. When $\beta_{2}$ is relatively large, then the effect of the past volatility on the current volatility requires relatively long time to vanish. $\beta_{3}$, on the other hand, is the "size effect" and measures the impact of a magnitude of a shock on the current volatility no matter what an unanticipated shock is positive or negative.

The choice of the conditional distribution of the disturbance term plays an crucial role when estimating the EGARCH $(1,1)$ model specified above. In finance literature, the GARCH Family models are mostly estimated by the assumption that the disturbance term, $\varepsilon_{t}$, followed a Gaussian (normal) distribution: $\varepsilon_{t} \sim N\left(0, \sigma_{t}^{2}\right)$. However, Mandelbrot (1963), Bollerslev (1986), Baillie and Bollerslev (1989), Hsieh (1989), Diebold and Nerlove (1989) stated that the distribution of the return series tends to be leptokurtic; that is, positive or negative extreme returns (outliers) appears more frequent than ones if the returns were distributed normal. Therefore, one needs to employ different distributions possessing fatter tails than normal distribution to model the leptokurtic return data. For example, the $t$ distribution has heavier tail

\footnotetext{
${ }^{11}$ VOLBUY includes both the CBRT buying auctions and direct foreign exchange purchases while VOLSELL includes the CBRT selling auctions and direct foreign exchange sales.

12 The daily dummy that takes the value of "one" for day i and zero otherwise is also included the model; however, it is excluded from the model since either the model convergence is not achieved or the coefficients are statistically insignificant.
} 
than normal distribution and converges to the normal distribution as the degree of freedom goes infinity. Similarly, Generalized Error Distribution (GED) has also fatter tails than the normal distribution with the shape parameter less than two. Even though EGARCH model with Gaussian distribution can easily involve the volatility clustering feature of the financial time series data, it is still not sufficient enough to model the return data which have leptokurtic distribution. Hence, Student's t distribution is employed to estimate the EGARCH model in this study ${ }^{13}$.

\section{Results}

Table 4. Daily Exchange Rate EGARCH Model: Conditional Mean and Variance Equations

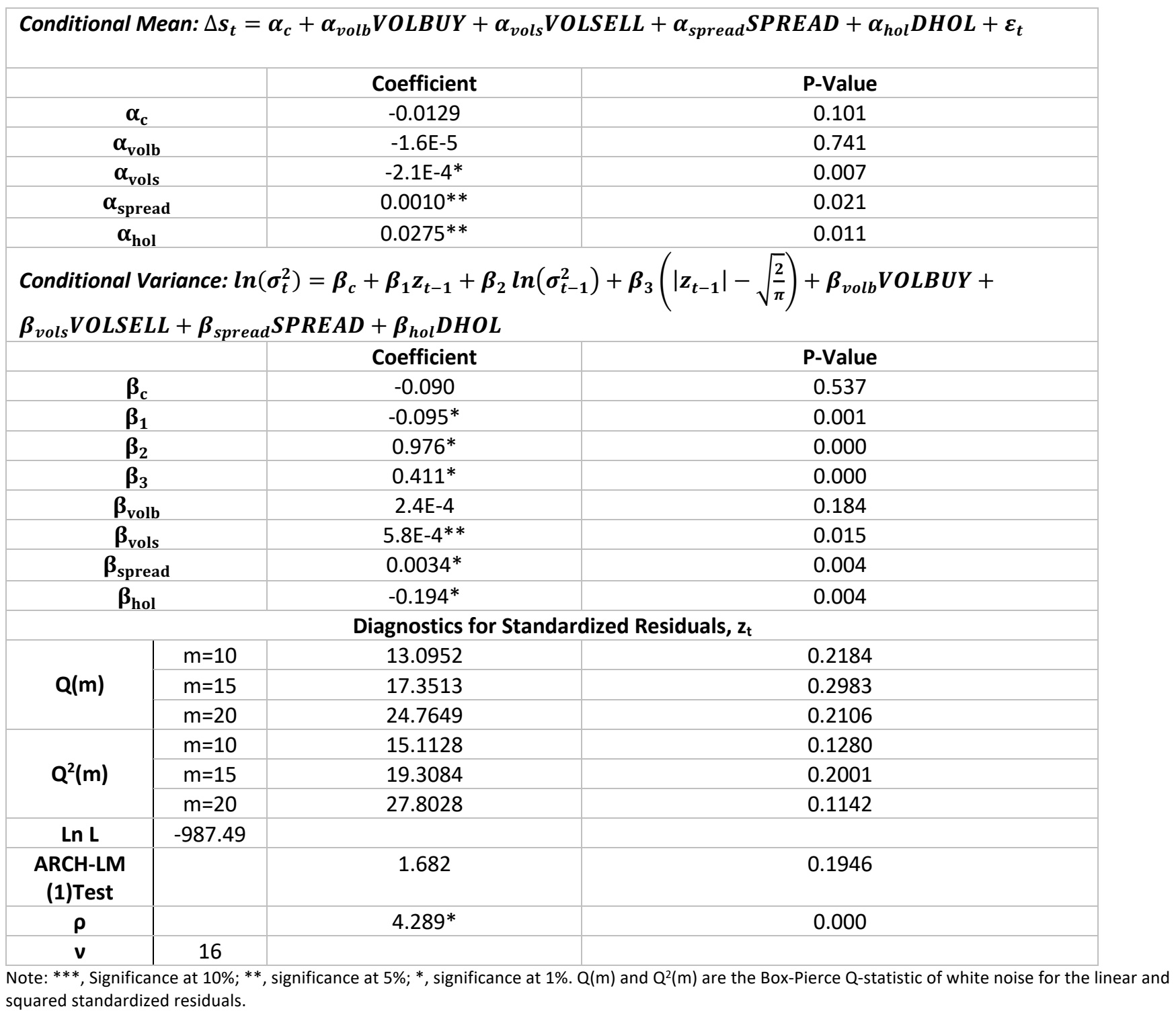

${ }^{13}$ The model is also estimated by using GED distribution; however, the convergence is not achieved during the maximization of log-likelihood process. One of the main drawbacks of the ARCHGARCH Models in practice is the difficulty of maximizing log-likelihoods. Hence, Student's t distribution is used in this study. 


\section{Conditional Mean}

VOLBUY and VOLSELL variables measure the impact of the CBRT's interventions on the exchange rate returns. The expected sign of the CBRT purchases on volatility is negative indicating that an increase in purchases lead to a depreciation of the TL (negative return) on the day of the purchase. Similarly, the expected sign of the CBRT sales is positive which represents the fact that an increase in sales lead to an appreciation of the TL (positive return) on the day of the sales. The sign of the interest rate differences or spread is expected to be positive; as spread increases, the foreign funds tend to flow toward the home country (Turkey) indicating that exchange rate increases or TL appreciates against the US dollar. Finally, there is not theoretically justified expected sign of holiday dummy variable on exchange rate returns.

The estimation results are reported in Table 4 and reveal that the CBRT's foreign exchange purchase operations have no statistically significant impact on the day of intervention. Similarly, the foreign exchange sales have a negative but statistically significant impact suggesting that the coefficient does not confirm the a priori expectation as mentioned above. The negative sign of the $\alpha_{\text {vols }}$ indicates a depreciation of the TL in response to a sale of the US dollar. That is, a sale of 1 billion US dollar leads to a $0.21 \%$ depreciation of the TL. This unexpected negative sign can be explained by "leaning against the wind effect" (see Baillie and Osterberg(1971), Tosini (1977), Edison (1993), Carlson and Kim (1994), Sarno and Taylor (2001)). That is, while the equilibrium price of the exchange rate is falling excessively (depreciation of TL), the CBRT attempts to reverse declining trend of exchange rate by selling foreign exchange. However, negative sign implies that the exchange rates do not follow the intention of CBRT's operations and keep continue to fall ${ }^{14}$. The most interesting finding of conditional mean equation of the

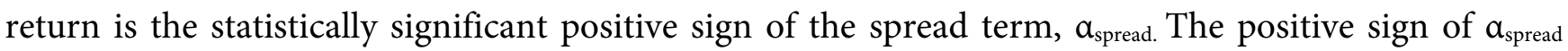
suggests an appreciation of TL against US dollar as expected a priori. If TL depreciates deeply, then the CBRT can trigger the interest rate policy and change the declining trend of the exchange rate to reduce the risks on financial stability. Finally, the holiday dummy variable has a significant positive sign suggesting an appreciation of the TL on the day following the market being closed for any reason. These evidences obtained from the conditional mean equation reveal two key outcomes. First, the CBRT interventions do not make any impact as what is actually intended by the CBRT in practice; conversely, the CBRT sales increase the negative returns and slightly accelerate depreciation of TL. Second, overnight interest rates clearly perform very well to drive exchanges rates as CBRT demands. The positive and significant coefficient of SPREAD confirms the a priori expectation in contrast to intervention variable VOLSELL. This result clearly points out that if the CBRT aims to get positive exchange rate returns, it should use interest rate policy rather than for intervening foreign currency markets.

${ }^{14}$ The reason of exchange rates not pursuing the CBRT's intervention attempts may be the credibility problem of the bank during the sample period. For example, Tuna (2011) stated that this unexpected sign may be arising due to the inadequate credibility of the CBRT or market inefficiency. 


\section{Conditional Variance}

The negative significant signs on the exogenous variables in the conditional variance equation represent a decline in the conditional volatility in response to a corresponding variable while the positive significant signs on the exogenous variables indicate a rise in the market volatility. The effects of intervention on the conditional volatility are shown in Table 4. The CBRT normally expects that reported interventions should reduce the exchange rate volatility during the periods when the bank announces its aim to calm markets. The results in Table 4, on the other hand, does not confirm the a priori expectation regarding the lower volatility. First, VOLBUY variable is statistically insignificant. Second, VOLSELL variable is statistically significant but positive indicating that the CBRT intervention sales slightly elevate exchange rate volatility. This might be viewed as a failure of the CBRT in its intervention objective to reduce volatility and involvement of CBRT in the market clearly adds to volatility ${ }^{15}$. Similarly, $\beta_{\text {spread }}$ is also positive and statistically significant inferring that a rise in the interest rate spread slightly increases the volatility of exchange rates. This also might be considered as a failure of the CBRT in its managing interest rate policy to reduce volatility. However, the negative and strongly significant holiday dummy variable reveals lower volatility on the day following the market being closed for any reason possibly due to information accumulation over the weekends and holidays. Negative and highly significant $\beta_{1}$ coefficient demonstrates the negative leverage effect; a large negative shock or unanticipated exchange rate decrease in the market is lead to higher volatility than a large positive shock or unanticipated exchange rate increase. Positive and relatively large $\beta_{2}$ parameter implies that the impact of past conditional volatility on current volatility is highly persistent. Finally, $\beta_{3}$ parameter is also statistically significant.

Several regression diagnostics are presented at the bottom of the Table 4: ln L represents the value of the log-likelihood function, and $v$ denotes the number of iterations that were needed to achieve model's loglikelihood convergence. The highly significant and relatively small degree of freedom parameter $\rho$ indicates that disturbances are not normally distributed. Additionally, $\mathrm{Q}(\mathrm{m})$ and $\mathrm{Q}^{2}(\mathrm{~m})$ are the BoxPierce Q-statistic to test of white noise with various lags for the standardized residuals and the squared standardized residuals, respectively. The results reveal that both standardized and squared standardized residuals obtained from EGARCH modelling of data are free from autocorrelation. Finally, ARCH-LM (1) test shows that one cannot reject the null hypothesis of no $\mathrm{ARCH}(1)$ effects in the standardized residuals. All diagnostic tests provide support for the EGARCH model with Student's t distribution and the data appear to fit the model very well.

\section{Concluding Remarks}

This paper investigates the effectiveness of the CBRT's operations during the float period, from 2002 to 2018. The results described in the previous section indicate that foreign exchange intervention policy does not have any success to drive the exchange rate returns as desired by the CBRT. The CBRT sales on a day tends to weaken currency. To put it more clearly, while the equilibrium price of the exchange rate is falling excessively, the CBRT efforts to reverse declining trend of exchange rate by selling foreign

\footnotetext{
${ }^{15}$ Also, Dominguez (1998), Baillie and Osterberg (1997), Kim et al. (2000), Beine et al. (2002) present evidence that central bank interventions significantly raised volatility of exchange rates despite the expected market calming effect of the interventions. Similarly, Tuna (2011) concludes that the CBRT's selling auctions significantly raises the volatility of exchange rates contradicting the its announcement.
} 
exchange is not followed by the agents and exchange rate still declines. Additionally, the CBRT purchases operations do not have any statistically significant impact on the exchange rate returns. A rise in overnight interest rates, on the other hand, increases the exchange rate. That is, the CBRT can reverse the declining trend of the exchange rate by increasing short run interest rates relative to the FED funds rate. This result indicates that if the CBRT aims to increase exchange rates, the bank should use interest rate policy rather than for intervening foreign currency markets.

The evidence presented in this paper indicates that intervention policy does not stabilize the volatility; while the CBRT sales on a day tended to raise volatility, the CBRT purchases do not have any statistically significant impact on the volatility. This result might be viewed as a failure of the CBRT in its intervention objective to reduce volatility of exchange rates. One of the more surprising results in the paper is that even though a rise in overnight spread relative to the FED's fund rate have success to reverse declining trend of exchange rates, it also slightly increases the volatility of exchange rates. This also might be considered as a failure of the CBRT in its managing interest rate policy to reduce volatility. In general, even though the CBRT is apparently quite willing to intervene the foreign exchange market during the float period, the results point out that CBRT's foreign exchange intervention policies are completely ineffective. However, the CBRT's monetary policy in the form of elevating the short run interest rates is functional for positive exchange rates returns; but not for reducing the volatility.

\section{References}

Akinci, Ö., Çulha, O. Y., Özlale, Ü., \& Şahinbeyoğlu, G. (2006). The effectiveness of foreign exchange interventions under a floating exchange rate regime for the Turkish economy: A post-crisis period analysis. Applied Economics, 38(12), 1371-1388.

Baillie, R.T. \& Bollerslev, T. (1989). The message in daily exchange rates: A conditional-variance tale. Journal of Business \& Economic Statistics, 7(3), 297-305.

Baillie, R. T. \& Osterberg, W. (1997). Why do central banks intervene? Journal of International Money and Finance, 16(6), 909-19.

Beine, M., Bénassy-Quéré, A., \& Lecourt, C. (2002). Central bank intervention and foreign exchange rates: New evidence from FIGARCH estimations. Journal of International Money and Finance, 21(1), 115-144.

Beine, M. \& Lecourt C. (2004). Reported and secret interventions in the foreign exchange markets. Finance Research Letters, 1(4), 215-225.

Beine, M. (2014). Conditional covariances and direct central bank interventions in the foreign exchange markets. Journal of Banking \& Finance, 28, 1385-1411. 
Black, F. (1976). Studies of Stock Price Volatility Changes. Proceedings of the American Statistical Association. Business and Economics Statistics, 177-181.

Bollerslev, T. (1986). Generalized autoregressive conditional heteroscedasticity. Journal of Econometrics, $31,307-32$.

Carlson, J. A. \& Kim, I. (1994). Leaning against the wind: Do central banks necessarily lose? Purdue CIBER Working Papers, Paper 86.

Çiçek, M. (2014). An evidence for ineffectiveness of central bank foreign exchange interventions from Turkey. Journal of Applied Finance \& Banking, 4(4), 39-54.

Dickey, D. A. \& Fuller, W. A. (1979). Distribution of the estimators for autoregressive time series with a unit root. Journal of the American Statistical Association, 74, 427-431.

Diebold, F. \& Nerlove, M. (1989). The dynamics of exchange rate volatility: A multivariate latent factor of ARCH model. Journal of Applied Econometrics, 4(1),1-21.

Dominguez, K. M. \& Frankel, J. A. (1993). Does foreign exchange intervention matter? The portfolio effect. American Economic Review, 83(5), 1356-1369.

Dominguez, K. M. (1998). Central bank intervention and exchange rate volatility. Journal of International Money and Finance, 17(1), 161-190.

Dominguez, K. M. E. (2006). When do central bank interventions influence intra-daily and longer-term exchange rate movements? Journal of International Money and Finance, 25(7), 1051-1071.

Edison, H. J. (1993). The Effectiveness of Central Bank Intervention: A Survey of the Literature After 1982. Special Papers in International Economics, No: 18. Department of Economics, Princeton University.

Engle, R. F. (1982). Autoregressive conditional heteroscedasticity with estimates of the variance of United Kingdom inflation. Econometrica, 50(4), 987-1007.

Fatum, R. (2008). Daily effects of foreign exchange intervention: Evidence from Official Bank of Canada data. Journal of International Money and Finance, 27(3), 438-454.

Frenkel, M., Pierdzioch, C., \& Stadtmann, G. (2005). The Effects of Japanese foreign exchange market interventions on the Yen/U.S. dollar exchange rate volatility. International Review of Economics \& Finance, 14(1), 27-39.

Gnabo, J. \& Lecourt, C. (2008). Foreign exchange intervention policy: With or without transparency? The case of Japan. Economie Internationale, 113(1), 5-34. 
Gök, İ. Y., Özkul, G., \& Özturk, E. (2016). Merkez Bankası müdahalelerinin döviz kurları üzerine etkileri: Türkiye üzerine ampirik bir araştırma. Finansal Araştırmalar ve Çalışmalar Dergisi, 15(8), 359-384. Hsieh, D. A. (1988). The statistical properties of daily foreign exchange rates: 1974-1983. Journal of International Economics, 24(1-2), 129-145.

Hsieh, D. A. (1989). Modeling heteroscedasticity in daily exchange rates. Journal of Business and Economic Statistics, 7(3), 307-317.

Kearns, J. \& Rigobon, R. (2005). Identifying the efficacy of Central Bank interventions: Evidence from Australia and Japan. Journal of International Economics, 66(1), 31-48.

Kim, S. J., Kortian, T. \& Sheen, J. (2000). Central Bank intervention and exchange rate volatilityAustralian evidence. Journal of International Financial Markets, Institutions and Money, 10 (2000), 381-405

Mandelbrot, B. B. (1963). The variation of certain speculative prices. Journal of Business, 36(4), 394-419.

Nelson, D. B. (1991). Conditional heteroscedasticity in asset returns: A New Approach. Econometrica, 59(2), 347-370.

Newey, W. K. \& West, K. D. (1987). A simple, positive semi-definite, heteroscedasticity and autocorrelation consistent covariance matrix. Econometrica 55(3), 703-708.

Phillips, P. C. B. \& Perron, P. (1988). Testing for a unit root in time series regression. Biometrika, 75(2), $335-346$.

Sarno, L. \& Taylor, M. P. (2001). Official intervention in the foreign exchange market: Is it effective and, if so, how does it work? Journal of Economic Literature, XXXIX, 839-68.

Schwarz, G. E. (1978). Estimating the dimension of a model. Annals of Statistics, 6(2), 461-464.

Shapiro, S. S. \& Wilk, M. B. (1965). An analysis of variance test for normality (complete samples). Biometrika, 52(3/4), 591-61.

Tosini, P. A. (1977). Leaning Against the Wind: A Standard for Managed Floating. Essays in International Finance, No: 126. New Jersey: Princeton University.

Tuna, G. (2011). The effectiveness of central bank intervention: Evidence from Turkey. Applied Economics, 43(14), 1801-1815.

Tunay, K. B. (2008). Türkiye’de Merkez Bankası müdahalelerinin döviz kurlarının oynaklığına etkileri. BDDK Bankacılık ve Finansal Piyasalar Dergisi, 2(2), 77-111.

Utsunomiya, T. (2013). A new approach to the effect of intervention frequency on the foreign exchange market: Evidence from Japan. Applied Economics, 45(26), 3742-3759. 
Westerfield, J. (1977). An examination of foreign exchange risk under fixed and floating rate regimes. Journal of International Economics, 7(2), 181-200. 